\title{
Exclusionary Rule of Illegal Evidence in China: Observation from Historical and Empirical Perspectives
}

\author{
Weimin Zuo and Rongjie Lan
}

\begin{abstract}
Although the use of torture and other illegal means to gather evidence was prohibited in China in 1979, legislators did not begin to embrace exclusionary rules until the turn of the 21 st century. However, this legislative promise has yet to be fulfilled in practice as few defendants request that illegally obtained evidence be excluded and even fewer judges approve such requests. Even if such a request is granted by the court, it remains highly unlikely that the outcome of the case will change. Such discrepancies between legislative endeavors and judicial practice might suggest that torture and other illegal means of acquiring evidence are not routine practice in China, that the Chinese culture tends to trust the government and to prefer substantive truth over procedural fairness, and places public interest above individual interests. As a result, the future of China's exclusionary rules will depend upon transformation of China's legal culture in addition to practical application of the corresponding changes to the law.
\end{abstract}

As an effective measure to defer police wrongdoings, exclusion of illegal evidence in criminal procedure, ever since articulated by the United States Supreme Court in Mapp versus Ohio, ${ }^{1}$ has emerged to be a core institution in any regime with genuine rule of law. The People's Republic of China (China), with the longest uninterrupted legal history in the world, has a legal legacy of obtaining evidence by coercive measures, and nowhere in its 2,000-year-plus documented history has seen the practice of excluding such evidence. After the Communist Party initiated the "Open-up and Reform" policy in late 1970s and endeavored to embrace universal principles and institutions of rule of law and human rights protection, legal academia

${ }^{1}$ Mapp v. Ohio, 367 US 643 (1961).

W. Zuo $(\square)$

Law School, Sichuan University, Chengdu, China

e-mail: zuowm@vip.163.com

R. Lan

Law School, Southwestern University of Finance and Economics, Chengdu, China

e-mail: lanrongjie@swufe.edu.cn

(C) The Author(s) 2019

S. Gless and T. Richter (eds.), Do Exclusionary Rules Ensure a Fair Trial?

Ius Gentium: Comparative Perspectives on Law and Justice 74,

https://doi.org/10.1007/978-3-030-12520-2_10 
and practitioners have since engaged in heated discussions of establishing exclusionary rules in China's Criminal Procedure Law (CPL). To better understand the status quo of China's exclusionary rules and their future, a careful observation of their history and an empirical analysis of their implementation is necessary.

\section{The Evolution of China's Exclusionary Rules}

\subsection{Budding Stage: 1979-1996}

Excluding illegally obtained evidence in China's criminal procedure is not a local tradition that can be traced back to China's long history. Despite the fact that the Communist Party has stated repeatedly in its policies that torture should not be allowed, the rules to exclude illegal evidence are still essentially a transplanted institution borrowed from the West, particularly the United States. That said, even compared with other transplanted legal institutions, such as presumption of innocence, right to counsel and right to public and speedy trial, exclusion of illegal evidence was also quite novel to most of China's legal practitioners and academia. But its roots can be traced back to the year of 1979, when China promulgated its first Criminal Procedure Law (CPL1979), 30 years after the Communist Party won national power from the Nationalists and established the People's Republic of China. Article 32 of CPL1979 prescribed, "torture, threat, inducement, deception and other forms of illegal methods of obtaining evidence are prohibited." The Criminal Code, which took effect in the year of 1980, also created the crime of torture in Article $136 .^{2}$ Nevertheless, whether such rules meant that evidence obtained through illegal methods would be excluded was unclear, not had there been any record showing any examples in which the court excluded evidence based upon findings that it had been obtained illegally.

One may argue that without excluding illegally obtained evidence, the practice of obtaining evidence with illegal methods can never be effectively deterred. Driven by desires to tackle crimes and put criminals behind bars, police officers, both good ones and abusive ones included, were sometimes inclined to use illegal but effective and productive methods to extract confessions or other evidence. Once the outcome proves correct, for instance, the true perpetrator being apprehended, the previous use of illegal methods may be completely ignored. After all, the public, and the authorities who pressured by public opinion, often prefer substantive correctness to procedural fairness. History has witnessed many of such examples.

\footnotetext{
${ }^{2}$ Art. 136 of the 1979 Criminal Code prescribed that "torture is strictly prohibited. Any state officer who extorts confession from a criminal by torture shall be sentenced to fixed-term imprisonment of not more than three years or criminal detention. If he causes injury or disability to the victim by using corporal punishment, he shall be convicted and given a heavier punishment in accordance with the provisions of the crime of assaulting."
} 
This argument is doubtlessly true. The history after the effectuation of CPL1979 has witnessed some violations of Article 32 without consequences. Several widely published wrongful murder convictions, including the cases of Nie Shubin ${ }^{3}$ and She Xianglin, ${ }^{4}$ for instance, all involved police torturing the defendants during interrogation, and some police officers were awarded for solving such difficult cases, while none received punishment until the wrongful convictions were eventually revoked.

That said, Article 32 of CPL1979 was nevertheless a remarkable milestone in China's progress toward abolishment of torture and introduction of exclusionary rules into its criminal procedure. CPL1979 was promulgated in the wake of the Cultural Revolution, a 10-year catastrophe that destroyed all legal institutions and resulted in hundreds of thousands of torture actions and unknown numbers of wrongful convictions and even executions. The minister and all his eight deputies of the Ministry of Public Security (MPS), China's police force, for instance, were all jailed and some were subject to torture when the Cultural Revolution began. When the National People's Congress (NPC) were debating CPL1979 and the Criminal Code, some delegates from the police department actually were against the ban on torture, claiming it would hinder the police from effectively fulfilling its duty to combat crimes. ${ }^{5}$ Indeed that by the time of 1979 , Chinese police force was in tremendous shortage of financial, technical and personnel support, and quite many police officers in the rank and file mainly relied on interrogation, and sometimes even torture, to investigate crimes. It was under such circumstances that Article 32 of CPL1979 was introduced, banning police torture but saying nothing about excluding evidence from torture or other police wrongdoings. It might look more like a toothless manifesto, but it well served a troubled country that was healing from a 10-year long catastrophe and desperately needed effective policing from an unqualified police force. Moreover, Article 32 of CPL1979 was not always toothless, as it could be, and sometimes have been, effectuated with combination of

\footnotetext{
${ }^{3} \mathrm{Mr}$. Nie Shubin was charged of raping and strangling a female worker in the farm near his house. He was convicted and executed in 1995, after making over a dozen of inconsistent confessions to the police through suspicious interrogations. In 2005, a career murderer was accidentally arrested by the police and confessed to the raping and murder of which Mr. Nie previously was convicted. Mr. Nie was finally exonerated in 2016. No police officer took responsibility for Mr. Nie's wrongful conviction and execution.

${ }^{4} \mathrm{Mr}$. She Xianglin was charged of murdering his wife after a quarrel, and a body claimed by the police to be his wife was discovered one month later in a nearby water pond. After a sleepless 5-day interrogation with brutal torture, Mr. She confessed to the murder and was later sentenced to 15 years in imprisonment. After serving almost 11 years of his term, his wife mysteriously came back in 2005. One police officer involved in Mr. She's investigation committed suicide after the exoneration trial, while no other officers were punished.
}

${ }^{5}$ PENG Zhen, 1979 at 2. 
Article 136 of the 1979 Criminal Code to punish certain forms of torture. ${ }^{6}$ In other words, in addition to demonstrating the legislators' explicit ban of torture, Article 32 of CPL1979 might still have imposed some real deterrence effect upon police investigation, but largely by punishing or even convicting a few abusive police officers, instead of by excluding illegal evidence.

However, tolerating police wrongdoings in practice may become addictive, as some police officers stop taking Article 32 of CPL1979 seriously and hesitate to explore non-coercive ways of criminal investigation, without which the legislature may never be ready to really ban torture and other illegal but effective means of evidence collecting. That kind of addiction was witnessed in 1996, when the NPC amended CPL1979 for the first time. Although many clauses of CPL1979 were revised, Article 32 remained intact. In fact, from 1979 to the beginning of the 21st century, another 30 years have passed since China wrote into its national law to ban torture for the first time, no more provision regarding excluding illegally obtained evidence has been added to any national laws. Only the Supreme People's Court (SPC) and the Supreme People's Procuratorate (SPP) issued two separate judicial interpretations in 1998 and 1999 and prescribed that all confessions or witness testimony obtained through torture, threat, inducement or deception shall not be used when prosecuting or convicting the defendant. ${ }^{7}$ Despite never adopted by national laws, the promises in these two judicial interpretations looked quite encouraging, in fact over-progressive even by today's standards, but neither the SPC nor the SPP further explained how such broad and ambiguous exclusionary rules should be implemented. Understandably, they would not, and largely could not be taken seriously in practice. Our research found no single case ended up in excluding illegal evidence under these two judicial interpretations. Not surprisingly, quite a few wrongful convictions still surfaced after 1996, including the cases of Zhao Zuohai ${ }^{8}$ and Du Peiwu, ${ }^{9}$ both of which involved obvious police brutality. In the Du Peiwu case, in particular, the defendant was in fact able to present a

\footnotetext{
${ }^{6}$ Although art. 136 of the 1979 Criminal Code seemed to criminalize all forms of torture, regardless severity or consequences, the SPP made it clear in a 1999 judicial interpretation that only those resulted in suicide or mental disorder of the victim, or causing wrongful convictions or other severe consequences should be prosecuted.

${ }^{7}$ See art. 61 of SPC's Interpretations regarding Multiple Issues in Applying Criminal Procedure Law (1998-23), and art. 265 of SPP's Rules of Criminal Procedure by the People's Procuratorates (1999-1).

${ }^{8}$ Very much similar to Mr. She's destiny, Mr. Zhao was charged of murdering one of his neighbors after a headless body was discovered and identified as Mr. Zhao's neighbor. He confessed to the police after a lengthy and coercive interrogation, and only regained his freedom 11 years later after the so-called victim came back alive.

${ }^{9} \mathrm{Mr}$. Du was a police officer and was charged of murdering his wife and her underground lover, both were also police officers and were shot in their car parking at a suburb park. Mr. Du confessed to the two murders after 11 days of torture, and was sentenced to death in the first instance trial. Several months after the appellate court commuted Mr. Du's sentence, the police arrested a serial killer by accident and the gun which was used to shoot the two victims was discovered in his possession.
} 
bloodstained shirt to prove the torture to the judges, but the trial court only turned a blind eye and never bothered to mention the shirt in its verdict and sentenced Mr. Du to death. ${ }^{10}$ The prohibition of illegal evidence in both CPL1979 and CPL1996, in this regard, seemed nothing more than a toothless manifesto and never meant to take effect in practice.

\subsection{Development Stage: 2010 to Date}

Despite CPL1996's inaction regarding excluding illegal evidence, quite many Chinese legal scholars and respected press kept pushing for legislative changes and calling for adoption of genuine exclusionary rules. The Internet has helped tremendously with enhancing such voice and spreading the idea of procedural fairness, as well as circulating scandals of police brutality. Quite surprisingly but understandably, after at least two decades of academic discussions and appeals, but almost suddenly from the year of 2010, probably due to the public outrage resulting from the surfacing of Mr. Zhao Zuohai's wrongful conviction and exoneration in that year, a flood of national legislations and policies regarding excluding illegally obtained evidence emerged in China and eventually pushed the practice into an unprecedented level.

(a) In 2010, the SPC, SPP, MPS, the Ministry of State Security (MSS) and the Ministry of Justice (MOJ) issued a joint regulation (JR2010) regarding excluding illegally obtained evidence in criminal procedure. This was the first time in the history of China's criminal procedure that the highest judicial authorities collectively proclaimed that illegally obtained evidence would be excluded from consideration of the court. Article 1 of JR2010 prescribed that "confessions of the suspect/defendant obtained by torture or other illegal means, as well as witness testimony or victim statements obtained by violence or threat are illegal testimonial evidence." No doubt that Article 1 alone looks similar to Article 32 of CPL1979, but Article 2 of JR2010 reads that "once such testimonial evidence has been confirmed illegal, it shall be excluded from being the foundation of judicial decisions." What makes JR2010 more important in legal history is the provision that once the defendant claims that his pretrial confessions were obtained illegally and successfully raises some doubt in the minds of the judges, the court shall order the prosecution to disprove that claim with sufficient evidence, otherwise the court shall exclude the confessions from consideration. In other words, when the legality of the procedure of obtaining pretrial confessions is under dispute, the burden of proof is on the prosecution side, although the defendant shall provide clues regarding

\footnotetext{
${ }^{10}$ The appellate court, citing "particular circumstances" of the case and "agreeable arguments" by the defense, commuted Mr. Du's death sentence to suspended death, indicating that the judges in fact believed the existence of torture during police investigation.
} 
when, where, how and who violated his rights. Many observers argue that this joint regulation is a remarkable breakthrough in China's judicial history, as for the first time not only tortured confession will be excluded, but also the defendant will not have to prove the torture, which in most cases is beyond the capability of the defense.

(b) In 2012, the Criminal Procedure Law was once again thoroughly revised by the NPC. A total number of five articles regarding exclusion of illegal evidence were added to this CPL2012. In general, all major provisions in JR2010 were adopted by the NPC, and for the first time, Article 54 of CPL2012 stated that the exclusionary rules apply to both testimonial and tangible evidence. However, not all tangible evidence obtained in violation of law is automatically excludable; instead, the court shall first look into how serious the violation will damage "judicial fairness," and whether such violation can be corrected or reasonably explained. Only those disputed tangible evidence that damages judicial fairness to a great extent and is not correctable or explainable shall result in exclusion.

(c) Following the promulgating of CPL2012, a serial of interpretations was issued by the SPC, SPP and MPS in late 2012, all adding details as to how to define illegal evidence and how to exclude illegally obtained evidence in judicial practice. The SPC specifically defined torture as "corporal punishment or disguised corporal punishment," and "other illegal means" as "measures that result in severe physical or mental pain or suffering and forcing the defendant to confess involuntarily" (Article 95 of SPC interpretation2012). Similarly, the SPP defined torture as "corporal or disguised corporal punishment that inflict severe physical or mental pain or suffering on the suspect," and "other illegal means" as "any measure that violates the law or coerces the suspect to a degree equal to torture, violence or threat" (Article 65 of SPP interpretation2012). SPP also defines the phrase of "damaging judicial fairness" when the legality of tangible evidence is in dispute. It provides that if tangible evidence is obtained by blatant violation of prescribed procedure, and may severely damage the fairness of judicial process, it shall be excluded unless the procedural violation is immaterial, correctable or can be logically and reasonably explained.

(d) In 2013, the Central Political and Legal Committee (CPLC) of the Chinese Communist Party (CCP) issued a resolution tackling wrongful convictions, reiterating the principle of excluding illegally obtained testimonial evidence. Although the words read almost the same as CPL2012, the uniqueness of this resolution comes from its issuing body, the highest political apparatus within the CCP coordinating judicial affairs among the courts, procuratorates, police and lawyers. It reflects the will of the ruling party, not only that of the legislature or the judiciary, so that it would certainly be better implemented in practice. Similarly, when the fourth Plenary Session of the 18th CCP Central Committee stated similar requirement in its official report in 2014, the will of the Communist Party to tackle wrongful convictions through excluding illegal evidence became unprecedentedly obvious and straightforward. 
(e) In 2016, the SPC, SPP, MPS, MSS, and MOJ promulgated a joint opinion to promote a trial-centered criminal procedure, requiring courts exclude evidence which was obtained in violation of existing laws. It appears that the central judicial authorities believe that only when the court is able to exclude illegally obtained evidence, even against protest of the prosecution or the police, that the trial can be considered the core of the criminal process.

(f) In April, 2017, the Central Task Force of Deepening Reforms (CTDR), the de facto highest decision-making body with President Xi Jingping as the head and a few top leaders as its members, unexpectedly issued a decree demanding strict exclusion of illegally obtained evidence in criminal procedure. This was encouraging for many of China's legal academia and practitioners, as very rarely the country's highest decision-making-body and top leaders have discussed criminal justice institutions, not mention such specific ones. Nevertheless, this unprecedented move by President Xi and his colleagues also indicated that exclusion of illegally obtained evidence is more difficult to carry out in practice than many have expected, therefore the direct involvement of the supreme leaders is warranted. Two months after the CTDR meeting, the SPC, SPP, MPS, MSS and MOJ promulgated another joint regulation (JR2017) emphasizing the exclusion of illegally obtained evidence. In this long-expected regulation, the five central judicial authorities stipulated that confessions obtained by threats of using violence or harming the suspect's or his families' lawful rights, as well as through illegal deprivation of the suspect's personal freedom shall all be excluded. In addition, once certain confession is deemed illegally obtained, any following confessions obtained under the influence of the previous illegal one shall also be excluded. Despite of these progresses, many observers were still disappointed by the fact that prolonged deprivation of sleep, as well as using of deception and inducement, are not explicitly considered illegal means of obtaining confessions by JR2017. That said, since JR2017 was only issued a few months ago and has yet been widely employed, it remains unclear how it would be implemented in practice.

\subsection{Observations of the Development of Legislations}

The development of China's legislations regarding exclusion of illegally obtained evidence from 1979 to 2017 results in the gradual institutionalization and localization of this important universal principle. CPL1979, emerging in wake of the catastrophic Cultural Revolution, illegalized torture and other coercive measures of obtaining evidence, but failed to clarify whether evidence obtained with such illegal measures should be excluded. As a result, although police wrongdoings were occasionally punished in accordance with CPL1979 and a corresponding article in the Criminal Code, no example of exclusion of illegally obtained evidence had been witnessed before the year of 2010, when the central judicial authorities issued the 
first joint regulation (JR2010) to tackle illegal evidence. Further legislations and policies, including the 2012 amendment to the CPL (CPL2012), the 2017 decree from the de facto highest decision-making-body, CTDR, as well as JR2017, all added details as to what evidence shall be considered illegal and how such evidence shall be excluded from criminal proceedings. In the end, the once empty promise of CPL1979 gradually gained practicability and enforceability.

Legal institutions do not grow by themselves. They are the result of the expansion of the general idea of rule of law and human rights protection, as well as the gradually increasing acceptance by the decision-makers and the public of procedural fairness, even with the cost of jeopardizing crime control. The accidental but inevitable emergence of wrongful convictions or even wrongful executions of innocent people in recent decades, combined with the exposure of police brutality and blatant violation of prescribed procedure, fueled by the powerful circulation of the Internet and social media, successfully sowed the seeds of human rights protection and procedural fairness in the minds of the public, and also forced the authorities, both judicial and political ones included, to tackle police wrongdoings in the criminal justice system. The concentration of legislations and policies after the year of 2010 regarding exclusion of illegally obtained evidence, was therefore a natural or even inevitable outcome of this combination of public opinion and government endeavors.

It is worth noting that China's legal scholars also contributed significantly to the introduction and development of exclusionary rules. Particularly in the wake of the 21 st century, faced by repeated emergence of wrongful convictions and police brutality, many criminal procedure scholars have continuously argued for the legislation and implementation of exclusionary rules. Some also conduct pilot experiments to test how such rules shall be carried out in practice and whether the mission of tackling crime would be jeopardized as a cost of excluding illegally obtained evidence. Many journal articles and books on this matter have been published, and many scholars have spoken out in the press to promote exclusionary rules. It is fair to say that the academia has always been a major driving force, although not the decisive one, for the development of exclusionary rules in China.

\section{Empirical Analysis of China's Exclusionary Rules: Are They Effectively Implemented in Practice?}

Concerning the tortuous legislative history of China's exclusionary rules, one can almost be certain to predict that the implementation of such rules in practice is never a smooth task. On the one hand, almost every legal system, code law countries in particular, have repeatedly witnessed the wide gap between the law in books and the law in action. On the other hand, as China's exclusionary rules only started to take shape in the 21st century and was first written in the CPL as late as in 2012, it may be too soon to conclude how they are implemented in practice at this point. 
That said, some general trends are ready for observation, which may help us evaluate the implementation of China's exclusionary rules, and predict how this universally important institution would develop in the future.

Empirical statistics regarding exclusion of illegal evidence are rare to see, due to both the short time since the emergence of the exclusionary rules and the government's reluctance to publish such information. The Supreme People's Court (SPC), however, did publish one set of simple numbers regarding how the exclusionary rules are implemented in practice. Earlier in 2017, with the purpose of promoting the use of big-data in the court system, one Associate Chief Justice of the SPC told the public that from 2014 to 2016, within 3 years, a total number of 2,765 cases involved exclusion of illegal evidence. This is not a very encouraging number, particularly if the total number of all criminal cases, over 3,238,000 during these 3 years, is taken into comparison. In fact, this number is only a little higher than the number of acquittals, which is, surprisingly but consistently, as few as 1,841 cases through all the 3 years. The statistics indicate that very likely the exclusionary rules are not effectively implemented all across China, at least not as satisfactorily as many have expected.

To better understand the implementation of exclusionary rules in China, we studied a pilot program in the western city of Chengdu from February 2015 to December 2016. The pilot program was designed under the broader reform called "trial-centered criminal procedure reform", aiming to reposition the trial as the core and decision-making stage of all criminal proceedings. Alternatively, this reform is also phrased as "substantializing criminal trial," indicating that previous trials are largely superficial. The titles also reflect that previous cases are often determined by police investigation, and the prosecution and the court are more like rubber stamps to confirm what the police claim, without imposing effective checks upon police wrongdoings. Such practice is popularly referred to as "investigation-centered criminal procedure," or "case-file-centered criminal procedure," as the prosecution and the court basically operate along with the case-file provided by the police, and in-court testifying of witnesses is rare to see in practice. ${ }^{11}$ In this program, 454 criminal cases were selected as experiment samples to be tried in the "trial-centered" way or in a "substantialized trial," while 336 cases were selected as control samples to be tried in the traditional manner. None of the sample cases were tried in summary procedure, which means that these cases either involved material factual or legal disputes or carried potential sentence of life imprisonment or death penalty. ${ }^{12}$ We also make use of another empirical study we conducted in 2013, one year after CPL2012 took effect. In that study, four courts in the same city of Chengdu were examined, including S Court at the provincial level, A Court at the

\footnotetext{
${ }^{11}$ ZUO Weimin, 2007 at 101.

${ }^{12}$ Art. 208 and 209 of CPL2012 provide that in basic courts, once a case involves no material factual disputes, nor it involves major social impact or mentally or physically retarded defendants, the court can try the case in a summary manner, which means the trial can be concluded in a few minutes.
} 
intermediate level, B Court at the urban grassroots level and C Court at the rural grassroots level. In addition, we interviewed some judges in the sample courts to verify or supplement our data. Below are some of our findings.

\subsection{Overall Trend: From "Extremely Cold" to "Modestly Warm"}

An experienced observer may infer from the repetitive legislations regarding excluding illegal evidence that the rules are not implemented well in practice, otherwise the legislators do not have to promulgate new laws with similar provisions again and again. Statistics reveal that in the "substantialized trials," 97 (or $21.37 \%$ ) out of all 454 experiment cases involved at least one defendant requesting exclusion of illegal evidence, while in the 336 control cases tried in traditional manner, only 15 cases (or $4.46 \%$ ) encountered such application. No doubt that these numbers seem very high, or probably excessively high, particularly for the experiment group. One critical explanation is that the majority of all criminal cases were in fact excluded from this program, as they involved no material disputes and the defendants all confessed to the charged crime. If we count in those undisputed cases that were tried with summary procedure, the percentage of defendants applying for exclusion of illegal evidence immediately dropped drastically. Figure 1 and Table 1 show a previous empirical study we conducted back in 2013 in four courts of the same city.

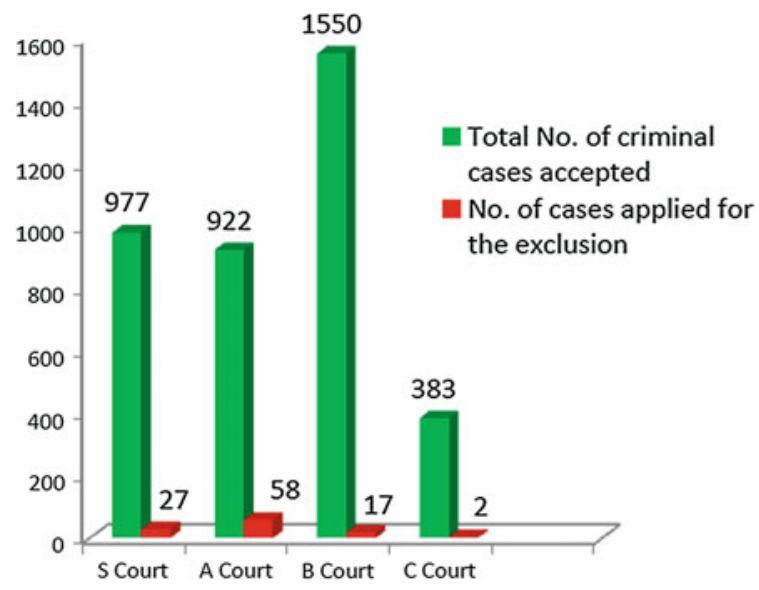

Fig. 1 Summary of cases with application by the defendant for exclusion of illegal evidence in the four sample courts (2013) (It should be noted that in Fig. 1, the number of cases in A Court was 468 in first instance of trial and 454 in second instance; while S Court did not handle criminal cases of first instance $(n=0)$, therefore, the number of cases handled in fact was the number of those in second instance) 
Table 1 Radio of cases with application for exclusion of illegal evidence in the four sample courts (2013)

\begin{tabular}{l|l|l|l|l}
\hline Contentlcourt & S Court (\%) & A Court (\%) & B Court(\%) & C Court(\%) \\
\hline $\begin{array}{l}\text { \% of cases without application } \\
\text { for exclusion }\end{array}$ & 97.2 & 93.7 & 98.9 & 99.5 \\
\hline $\begin{array}{l}\text { \% of cases with application } \\
\text { for exclusion }\end{array}$ & 2.8 & 6.3 & 1.1 & 0.50 \\
\hline
\end{tabular}

Combining the two sets of statistics, we can conclude that although the overall numbers of cases involving application of exclusion of illegal evidence are still low, the exclusionary rules are taking up momentum in disputed cases, particularly in those selected by the court to test a new style of substantialized trial. Indeed, prior to the 2010 joint regulation of excluding illegal evidence, the environment for application for excluding illegal evidence was so cold that we barely witnessed any examples, but the introduction of new laws and policies have heated up the environment and more and more applications for excluding illegal evidence are emerging in practice. In other words, we can at least conclude that the atmosphere of excluding illegal evidence has progressed from "extremely cold" to "modestly warm".

One may ask why the substantialized trials saw much more applications of exclusion of illegal evidence. The answers are four-folded, although all rest on the fundamental objective that the trial itself, not the police investigation or the prosecution, shall be the core of the entire criminal procedure and the incubator of the final decision. First, the participation of defense lawyers, either hired by the defendant or appointed by the court, is required in all substantialized trials, which enables the defense to pinpoint illegal evidence and launch persuasive applications for exclusion. Second, a special mechanism is designed to accommodate filing motions for exclusion of illegal evidence in pretrial conferences and debating for suppression in a built-in hearing at the beginning of the trial. The implementation of exclusionary rules thus becomes a mini-trial within the regular trial, forcing the court and the prosecution to respond to claims of the defense regarding illegal evidence. Third, when debating the lawfulness of evidence gathering process, the prosecution is often required to present the audio/video recording of pretrial interrogations, and police officers conducting the investigations, including the interrogators, are all subject to summon by the court to testify in person, which may have given significant confidence and incentives to the defense for bringing about allegations of illegal evidence. Forth, a substantialized trial means that the collegial panel sitting on the bench is indeed the sole decision-making body of the case, and its decision often comes right after the conclusion of the trial and the completion of the deliberation among the members of the panel. As a result, the final verdict of the court is more likely to be shaped by the trial, and the defendant and his lawyer stand a better chance to influence the decision-makers through in-court activities, which encourages them to retract pretrial confessions on the ground of torture or other 
illegal means. In short, the reform of substantializing criminal trials paves way for exclusion of illegal evidence, and in return, the exclusion of illegal evidence by judges demonstrates that the trial is indeed a substantive incubator for court verdicts, not a rubber stamp to confirm what the police and prosecutors allege.

\subsection{Defendants Increasingly Apply for Exclusion of Illegal Evidence, and Chances of Success Are Low but Growing}

True that almost in all countries with exclusionary rules in their criminal procedure, defendants and defense lawyers apply for exclusion in quite many cases, but quite rarely the court grants suppression of illegally obtained evidence. In the 454 experiment cases of 2015 and 2016, 97 cases (21.37\%) involved at least one defendant applying for exclusion of illegal evidence, among which 66 cases (68.04\% of all applications, or $14.54 \%$ of all cases) ended up in refusal by the court, while only 12 cases $(12.37 \%$ of all applications, or $2.64 \%$ of all cases) were accepted in entirety, and another 18 cases $(18.56 \%$ of all applications, or $3.96 \%$ of all cases) received partial acceptance. In the control group, 8 of all the 15 applications $(2.38 \%$ of the total number of sample cases) were rejected by the court, and the other 7 cases (or 2.08\%) received partial acceptance. Similarly, as revealed by Table 2, in our 2013 study, only $9.6 \%$ of all applications of exclusion of illegal evidence succeeded, which counted $0.3 \%$ of all criminal cases heard by the sample courts.

It seems that in substantialized trials, the defense was not only more willing to apply for exclusion of illegal evidence, they also stand a relatively better chance $(2.64 \%+3.96 \%=6.6 \%)$ than in a traditional trial $(2.08 \%)$ to win a favorable decision from the court. Nevertheless, even excluding those substantialized trials, defendants in 2015 and 2016 had over 7 times more chances to exclude illegal evidence than those in 2013 (2.08\% versus $0.3 \%)$. In other words, the exclusionary rules steadily gain popularity and effectiveness after it was written into CPL2012. Not only more defendants are inclined to utilize the rules, but also more courts are willing to realize their promise.

Table 2 Ratio of cases with exclusion of illegal evidence in the four sample courts (2013)

\begin{tabular}{l|l|l}
\hline Courts & $\begin{array}{l}\text { \% of cases with exclusion } \\
\text { in all criminal cases }\end{array}$ & $\begin{array}{l}\text { \% of applications for } \\
\text { exclusion succeeded }\end{array}$ \\
\hline S Court & 0.2 & 7.4 \\
\hline A Court & 0.7 & 12.1 \\
\hline B Court & 0.06 & 41.2 \\
\hline C Court & 0 & 0 \\
\hline Total & 0.3 & 9.6 \\
\hline
\end{tabular}




\subsection{Courts Excluded Much More Testimonial Evidence Than Tangible Evidence}

Among those 454 experiment cases tried in a substantialized manner, 30 cases (or $6.6 \%$ ) resulted in exclusion of all or some of the disputed evidence. 5 exclusions involved tangible evidence, while all the rest only dealt with testimonial evidence, particularly confessions of the defendants. This disparity also exists in the applications for exclusions of illegal evidence. Among the 97 applications, 62 cases (or $63.92 \%$ ) requested for exclusion of pretrial confessions by the defendants. 23 (or $23.71 \%$ ) targeted pretrial witness testimony or victim statements. Only 12 applications (or $12.37 \%$ ) asked the court to quash tangible evidence. Interestingly, no expert testimony was disputed to the extent warranting an exclusion application. In one word, both the parties and the court prefer challenging testimonial evidence, while tangible evidence is less frequently disputed.

As mentioned above, CPL2012 prescribed that when judicial fairness is severely jeopardized by violation of established procedure in the process of obtaining tangible evidence, and the damages are not correctable or reasonably explainable, the court shall suppress the evidence as well. In practice, however, not very often that the defense is able to launch such an application, and even less often that the court will grant exclusion. The main reason is two-folded: one is that Chinese police are widely permitted to conduct warrantless searches and seizures, and two is that China lacks a rigid requirement of chain of custody for tangible evidence. As a result, not very likely the obtaining of tangible evidence would fall into the gap of violating prescribed procedure and severely damaging judicial fairness. On the contrary, due to the lack of the right to silence and the right to counsel during interrogation, criminal suspects are routinely subject to police interrogation, sometimes coercive or even violent in nature, in almost all cases, and the majority confess to the police at very early stage. When their cases finally reach the court and face eminent conviction and punishment, some defendants are often desperate to plea for suppression of pretrial confessions, as this may be their last savior.

It is worth noting that compared with suppressing tangible evidence, judges are more comfortable with excluding confessions. After all, illegally obtained confessions often involve significant possibility of falseness, while tangible evidence collected in violation of prescribed procedure runs little risk of telling a lie. In addition, untrustworthy confessions are rectifiable, for instance, by questioning the defendant again in the open court, without using any coercion or threat, but obtaining tangible evidence is usually a one-shot game, bearing little likelihood of redoing. As a result, judges exclude more confessions than tangible evidence.

The most recent regulation regarding exclusion of illegal evidence, JR2017, issued by the five judicial authorities of the central government, prescribed that not only confessions obtained by torture, but also following confessions obtained under the influence of the previous tortured confession, shall both be excluded. In addition, threats of using violence or harming the suspect's or his families' lawful rights, as well as illegal deprivation of personal freedom, are all prohibited in police 
interrogation, and could also result in exclusion of the confessions so obtained. In this regard, one can easily predict that as JR2017 being implemented in practice, more applications for quashing testimonial evidence will emerge and the court will exclude more of such testimonial evidence.

\title{
2.4 Most Defendants Prefer Challenging Illegal Evidence Only at the Trial Stage
}

\begin{abstract}
Although both CPL2012 and JR2017 state that not only the court, but also the police and prosecution are obliged to exclude illegal evidence, real exclusions seldom occur in the investigation and prosecution stages, and most exclusions are effectuated by the court. In fact, in our statistics no single evidence was excluded by the police or prosecutors. It is true that only the court publishes its opinions, thus even if some exclusions occur in earlier stages, there would be no official record available to the public. Our interview with prosecutors and police officers revealed that occasionally and increasingly, the prosecution also excludes illegal evidence, and sometimes such exclusion would result in the dismissal of criminal charges. Nevertheless, due to the fact that most defendants only hire their lawyers in the trial stage, and that most lawyers still prefer fighting the prosecutors in the courtroom (including pretrial conferences), implementation of the exclusionary rules in pre-trial stages is still rare.
\end{abstract}

\subsection{Few but Increasing Numbers of Exclusions of Illegal Evidence Impact Case Outcomes}

It is true that the life of exclusionary rules depends on its deterrence effect upon police wrongdoings, not on benefitting the accused. However, if exclusion of illegally obtained evidence only leads to taking away some evidence from the prosecution's case file, without significantly weakening or jeopardizing its case, very likely the police and prosecution may not feel deterred. In this regard, effective exclusionary rules often mean not only suppressing some evidence, but also forcing out some charges or even the entire case. Without the latter effect, the exclusionary rules are nothing more than a beautiful but useless show.

Among the 30 experiment cases tried in a substantialized manner and involved actual exclusion of prosecution evidence in 2015 and 2016, 4 cases (or 13.33\%) were reported to have major impact upon conviction and sentencing, 17 cases (or $56.67 \%$ ) left some impact, while 9 cases (or 30\%) did not change anything about conviction or sentencing. However, the courts did not illustrate what constitutes major or minor impacts. One thing for sure is that no case resulted in acquittal, although some cases ended up in the prosecution's partial withdrew of charges. 
Our fieldwork in 2013 collected 10 cases with actual exclusion of prosecution evidence, none of which changed the conviction. 8 of the 10 cases involved exclusion of the defendants' pretrial confessions, but the remaining confessions and other evidence still support a conviction. 2 of the 10 cases excluded expert opinions, and the prosecution simply provided another expert opinion to support the same conclusion.

The disparity between the numbers of excluding illegal evidence and the numbers of changing case outcomes indicates that when judges ponder over whether to exclude certain evidence, they often have the final verdict in mind. For instance, several judges frankly admitted in our interview that their decision of excluding illegal evidence mainly depends on "whether or not the exclusion will cause any effect on the conviction and sentencing." 13 In other words, whether the evidence is indeed illegally obtained is not the key factor dictating the application of the exclusionary rules. Judges care more about the final outcome of the case, particularly whether the defendant will still be convicted given the disputed evidence being excluded. One judge even stated to us in the interview that "we only decide to exclude certain illegal evidence on the condition that other evidence (especially repeated statements) can support the conviction and sentencing, while we will be very careful and generally will not exclude such illegal evidence when it may affect the case and cannot be regenerated in nature."

As mentioned above, more often pretrial confessions of the defendant are to be excluded in practice, usually on the basis of using torture or other means of coercive interrogations. As direct evidence to inculpate the defendant, pretrial confessions are often the key to convict the defendant. With such critical evidence being excluded, how does the prosecution rebuilt its case and secure a conviction? More importantly, if the court only intends to exclude the coerced confessions but determines to convict the defendant anyway, how does it justify its decisions in a written opinion that will be open to the public? One way is to rely on circumstantial evidence to build a "chain of evidence" capable of supporting a conviction, which is quite rare in practice. The other way is to rely on repeated confessions of the defendant, including both in-court ones and pretrial ones. JR2017 provides that repeated confessions obtained under the influence of previous tortured confession are inadmissible, but if the repeated confessions are obtained by different interrogators or at different stages, and the defendant has been informed of his rights and consequences of confessing, they shall be admissible. As a result, when judges decide to exclude certain pretrial confessions of the defendant, they can still rely on his later confessions made to different interrogators to convict him. The exclusion looks more like an empty check to the defendant, as it brings in nothing but false hope. What's worse, once the police learnt the trick, they may easily modify their interrogation tactics and change interrogators after torturing the suspect, so that later confessions of the suspect are still admissible and capable of ensuring a conviction in the court. In this regard, the effectiveness of the exclusionary rules depends on

\footnotetext{
${ }^{13}$ See, e.g., interviews with Judge Q in S Court; Judge L in B Court; Judge Z in C Court.
} 
the skillfulness of police wrongdoings and willingness of judges to look beyond the text of the rules into the true nature of police interrogations, which is, at least in most cases too demanding.

However, if the exclusion of illegal evidence has potential major impact on the conviction or sentencing, judges often prefer delaying the case for some time and request the prosecution to submit supplemental evidence to replace the excluded evidence. After all, acquitting a defendant usually means a slap in the face of the prosecution, which will not only result in the embarrassment of the prosecutor and his department, but also bring in fierce counter-attack from the prosecution in some cases. As comrades of the same battlefield to combat crimes, judges often feel reluctant to force fellow prosecutors into such a difficult position. Instead, if judges really believe that a defendant shall be acquitted as a result of excluding illegal evidence, they often will ask the prosecution to withdraw the case to avoid an acquittal. It is true that our research did not find any of such withdrawals arising from the exclusion of illegal evidence, but our experiences and observations tell us that this is often how the court and prosecution deal with substantively not-guilty cases.

\title{
3 What Causes the Gap Between Exclusionary Rules in the Books and in the Action?
}

\begin{abstract}
Above empirical studies reveal a huge gap between legislation and practice of exclusion of illegal evidence. The legislature has been busy writing laws and policies to realize excluding illegally obtained evidence, but the judges move much slower, particularly before the reform of substantializing criminal trials. Lawyers are enthusiastic to utilize the exclusionary rules to vigorously defend their clients, while judges are reluctant to suppress the prosecution's evidence, not mention throwing out the charges. Generally speaking, despite being loudly promoted by the legislature, the academia and defense lawyers, exclusion of illegal evidence is still rare in practice, and no sign of drastic increase is seen in the near future. In other words, the gap between legislative promises and judicial practice will continue to exist for a long time, probably much longer than we have expected. Two questions worth asking are: what are the causes of such a gap? And what will be its future?
\end{abstract}

\subsection{Police Wrongdoings Are Not Routine in China}

The number one explanation for these surprising phenomena is that lawfully obtaining evidence is the main stream of China's criminal procedure, while torture, threat, deception or other illegal measures are indeed exceptions, although not entirely in absence. Specifically, critical evidence in most cases, such as the confession of the suspects, or the drug or gun in possession of the suspect, are often obtained in accordance with the law and related regulations. This trend becomes 
more obvious in recent years, as criminal investigation and evidence gathering become more institutionalized and standardized, and more technical and financial support is provided to assist police investigation. For instance, within the past few years, the Ministry of Public Security completed a historic task to install cameras and other recording equipment in all interrogation rooms of every police station within China, which, combined with the new provision in CPL2012 that all but exceptionally emergent interrogations shall only take place in such interrogation rooms, significantly reduced the number of tortures in the grass level, as stipulated by many practitioners and observers. In fact, allegations of police torture are in sharp decrease in the courtrooms, although many defendants still claim deprivation of sleep in police interrogations.

Comparative studies reveal that in all mainstream legal systems of the entire world, excluding illegally obtained evidence has always been exceptions, instead of routine practice. China may have lagged in the history, but after over two decades of reforms toward rule of law, it has improved its record in protecting human rights and gradually catching up with mainstream countries. The exclusionary rule is more of a weapon for deterrence, instead of for real punishment. ${ }^{14}$ It matters as it exists and can be utilized if necessary, not as it takes effects in as many real cases as possible. In this regard, the gap between legislative promises and judicial practice regarding China's exclusionary rules is indeed quite normal, and shall persist in the foreseeable future as well.

\subsection{Discord Between Chinese Culture and Implanted Institutions}

Exclusionary rules are basically implanted institutions in China. Many legal implantations fail, largely due to the fact that translating the text of legal rules alone does not guarantee a successful implantation. Legal rules are embedded deeply in a given society, reflecting its history, culture, economy and power structure. Planting the same rules in another jurisdiction of different settings runs a considerable risk of collision and rejection. Certainly, the government can write certain foreign rules into local laws, but whether such rules can be effectively implemented in practice depends on the degree of compatibility between the translated rules and local conditions. As soon as exclusionary rules are concerned, despite the many similarities between China and the West, we have also seen quite a few discords, which may help explain the gap between legislative promises and judicial practice discussed above.

\footnotetext{
${ }^{14}$ See, e.g., United States v. Leon, 468 US 897, 916 (1984) (“[T] he exclusionary rule is designed to deter police misconduct ..."); Elkins v. United States, 364 US 206, 217 (1960) ("The rule is calculated to prevent, not to repair. Its purpose is to deter- to compel respect for the constitutional guaranty in the only effectively available way — by removing the incentive to disregard it.").
} 


\subsubsection{Trusting the Government Versus Guarding Against the Government}

The logic of excluding illegal evidence is essentially a tradeoff between combatting crimes and tackling police wrongdoings. In the United States, for instance, where the exclusionary rules originated, a widely accepted idea is that compared to the crimes committed by individual citizens, the abuse of power by the government itself, particularly its armed apparatus, is way more dangerous and damaging, thus warrants more precautions. Accordingly, when a police officer violates the legal rights of a suspect and obtains sufficient evidence to convict him, it is more important to deter any further police wrongdoings than putting the criminal behind bars. It is upon such social, cultural and political consensus that the exclusion of illegally obtained evidence is acceptable, even if it means a true perpetrator who has been spotted and apprehended by the police must be set free.

The social consensus in China, however, is significantly different. The Chinese civilization has a long history of trusting the government, which is oftentimes referred to as the protector or guardian of the people, and government officials are sometimes called "parents-officials," meaning that they shall act for the best interest of the people, although sometimes it requires being tough. In some situations, as long as the government acts with right intention, even if what it does is indeed wrong, the people may nevertheless readily forgive it. Particularly, when it goes to the criminal justice system, average people are more willing to grant police officers as much flexibility and convenience as necessary to fight against criminals. Minor violation of laws and rights of the suspects are largely tolerated, if not awarded, as long as they catch the right person. In fact, many people believe that coercion and even violence is an indispensable component of criminal investigation and rehabilitation, just like a successful child often needs tough discipline of a "tiger mother." Excluding prosecution evidence due to police wrongdoings and consequently setting a known criminal free is hard to understand for many Chinese people. This explains, at least partially, why Chinese judges are reluctant to enforce the exclusionary rules and even if they do exclude some prosecution evidence as required by the law, very rarely they will acquit the defendant.

\subsubsection{Substantive Truth Versus Procedural Fairness}

Excluding illegally obtained evidence means that in some cases the substantive truth could be sacrificed, and a factually proven criminal could be set loose. As a trade-off, the integrity of the criminal procedure is preserved and enhanced. No surprise that the exclusionary rules were first articulated in the United States, where the principle of due process is the fundamental foundation of legal institutions and is widely accepted or even worshipped by the public. To some degree, due process of law has become an ideology of the United States, as well as in some other Western countries with mature rule of law. The public, the government and the judiciary often see no problem if the objective truth of an individual case must be 
compromised to maintain the fairness of judicial procedure. As Francis Bacon once said, "one foul sentence does more hurt than many foul examples. For these do but corrupt the stream;the other corrupt the fountain."15

The Chinese tradition, however, seems to value substantive truth more than procedural fairness. One widely circulated proverb reads "truth is beyond all." In Chinese legal history, as well as in contemporary legal fictions and movies, the best judges have always been those with exceptional skills to discover the truth while extending sympathy and kindness to those weak and suffering. Average Chinese people still believe that it is the responsibility of the court to probe into the confusing mist of evidence and ascertain the truth. In fact, back in the early 2000s, when the development of civil procedure required imposing the burden of proof on the parties, and judges began to refuse to conduct their own investigation outside of the courtroom and simply decide against the party who failed to fulfill his burden of proof, many people contended that the court was shifting its duty and was no longer a "People's court."

Understandably, the preference for substantive truth is often in conflict with the exclusionary rules. When tangible evidence is obtained in violation of law, for instance, it still possesses the same value of proving the case. A truth-minded tribunal may choose to admit the evidence and convict the defendant, while a fairness-minded tribunal is more likely to suppress the evidence and set the defendant free. Certainly, no system is that simple, and the exclusion of tangible evidence is often case-specific, requiring consideration of many conflicting values in each individual case. Nevertheless, the general preference of substantive truth or procedural fairness still makes huge difference.

\subsubsection{Individual Rights Versus Public Interest}

Excluding illegally obtained evidence means that in some cases public interest could be sacrificed to preserve personal rights. The deterrence effect of the exclusionary rules in fact rests on such a dilemma. Only when a police officer cares about failing to convict the suspect in the court, that he would choose to follow the rules and avoid violating the suspect's legal rights. Nevertheless, whenever a judge suppresses critical prosecution evidence and acquits a factually guilty defendant, he is also putting the public in danger. The logic seems to be that when a police officer makes mistakes, the public is paying for the costs. In a country where individual rights are upheld high, such a tradeoff may be acceptable. But in another jurisdiction that cherishes public security more than individual freedom, public resistance may become a major obstacle when introducing the exclusionary rules into the law.

The Chinese culture has a long history of preferring public interest to personal rights. Popular slogans of the Chinese society include "sacrifice personal interest and serve the many" and "collective interest out-values individual interest."

\footnotetext{
${ }^{15}$ Bacon, 1983 at 64.
} 
In certain phrase of the history of the People's Republic of China, simply talking about personal interest was considered a shame. The transition from a planned economy to a market-oriented economy starting in the late 1970s drastically changed the social attitude, and pursuing of personal interest in current China is no longer a disgrace. Nevertheless, in public debates over major social policies, the traditional pro-public-interest discourse still returns frequently. Understandably, when it goes to whether a guilty criminal should be set free because of mistakes made by the police in gathering evidence, many would choose to protect public security and put the defendant in jail, probably with a lesser sentence.

\section{The Future of China's Exclusionary Rules}

\subsection{Overall Assessment}

Exclusion of illegally obtained evidence is basically new in China, particularly if China's 2,000+ years of legal history is taken into the calculation. Yet in only less than 40 years, China has inputted tremendous legislative efforts to implant and implement the rules of excluding illegal evidence, to the extent that even the de facto highest decision-making body and the most powerful state leaders of this mega country were directly involved in the legislative process. Certainly, progress in the books does not necessarily reflect the behavioral changes in the practice, but the continuous pushing from the legislators, academics and practicing lawyers, combined with the public outrage over surfaced wrongful convictions, will doubtlessly result in wider acceptance of the conception of excluding illegal evidence, and will eventually lead to better effectuation of the exclusionary rules. However, due to China's long history of prioritizing substantive truth and public interest against procedural fairness and individual rights, as well as the increasing crime rate China is facing, the exclusionary rules will not be as effective as expected.

That said, as China's legal culture and judicial practice transforms gradually, the exclusionary rules may become more prominent in the future. The last three decades have witnessed the growing acceptance of jeopardizing crime control to accommodate due process of law, not only within the academia and the legal circle, but also among the often more conservative general public and political circle. The Internet has played a remarkable role in this process, particularly by circulating scandals of wrongful convictions and stimulating discussions of procedural solutions. The introduction and rapid spreading of more advanced technologies of criminal investigation, including DNA testing and camera surveillance, have also helped reducing the demand for illegal means to obtain evidence. If we would to believe that exchange of information, especially that about scandalous government actions, will become freer and more convenient in the future, and that criminal investigation will more depend upon scientific and technical measures, we shall then believe that China's exclusionary rules will be better implemented in the future. 


\subsection{Short-Term and Long-Term Projections}

In the short term, the development of China's exclusionary rules depends on the development of China's criminal procedure. For instance, earlier involvement of prosecutors in the process of criminal investigation will often improve the chance of convicting the suspect while deterring police wrongdoings. A trial-centered criminal procedure that produces a criminal verdict through an orally conducted trial is more likely to exclude previously transcribed confessions or witness testimony. Sending more lawyers to attend criminal trials and pushing for effective defense will generally result in more exclusions, too. Such procedural improvements can be largely accomplished by legislations at the national or local levels, and we can expect fast behavioral changes in the practice once such mechanisms are institutionalized.

In the long term, however, the future of China's exclusionary rules depends upon the transformation of China's legal culture. After all, exclusionary rules are basically a common law institution, and even in UK or US, they are not frequently applied in practice. Fewer applications can be found in continental countries in Europe. In this regard, the future of China's exclusionary rules eventually depends upon the degree of concord or discord between implanted institutions and local legal culture. Fortunately, the pursuits of procedural justice and personal rights in China have been rapidly growing for decades, and no sign has been confirmed that such pursuits would go into an end in the future. As a result, in the long run, public acceptance of exclusionary rules will be more satisfactory and implementation of such rules in practice will be easier and less costly.

\section{References}

Francis Bacon, 'Of Judicature', (1983) 9 Litigation, 64, 53-54 [Bacon, 1983].

彭真 (PENG Zhen): 在全国检察工作座谈会、全国高级人民法院和军事法院院长会议、第 三次全国预审工作会议上的讲话 (Remarks at the National Conference of Prosecutorial Affairs, High Court Presidents, Military Court Presidents and the Third National Conference on Investigation Works), 人民司法 (Renmin Sifa), 1979-10, 1-5 [PENG Zhen, 1979].

左卫民 (ZUO Weimin): 中国刑事案卷制度硎究——证据案卷为重心 (On the Criminal Dossiers System of China: Focusing on the Evidence Dossier), 法学㸴究 (Faxue Yanjiu), 2007-6, 94-114 [ZUO Weimin, 2007]. 
Weimin Zuo serves as the Dean of Sichuan University Law School and the Vice Chair of China Society of Criminal Procedure. He has published over 100 articles in major Chinese law journals, covering the topics of criminal procedure, judicial reform and dispute resolution. In recent years he has focused on empirical legal research and has led a number of projects investigating judicial practices in China.

Rongjie Lan received a Ph.D. in Law from Sichuan University in China and a SJD from Temple University in the USA. His research focuses on Chinese criminal procedure and evidence law, and he has published over two dozen articles and books in both Chinese and English. During his teaching, he also served as an adjunct judge and later an adjunct prosecutor.

Open Access This chapter is licensed under the terms of the Creative Commons Attribution 4.0 International License (http://creativecommons.org/licenses/by/4.0/), which permits use, sharing, adaptation, distribution and reproduction in any medium or format, as long as you give appropriate credit to the original author(s) and the source, provide a link to the Creative Commons license and indicate if changes were made.

The images or other third party material in this chapter are included in the chapter's Creative Commons license, unless indicated otherwise in a credit line to the material. If material is not included in the chapter's Creative Commons license and your intended use is not permitted by statutory regulation or exceeds the permitted use, you will need to obtain permission directly from the copyright holder.

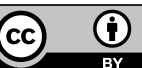

